\title{
PREPARAÇÃO FÍSICA NO FUTEBOL: CONTRIBUIÇÕES PARA O RENDIMENTO DO ATLETA
}

\section{PHYSICAL REPAIR IN SOCCER: CONTRIBUTIONS TO ATHLETE'S PERFORMANCE}

\author{
Pedro Mário Menezes Mendonça \\ Bacharel em Educação Física, \\ UniAGES Centro Universitário, Paripiranga-BA, Brasil \\ E-mail: pedro22.pm7@gmail.com \\ Davi Soares Santos Ribeiro \\ Mestre em Educação Física (UFS) \\ UniAGES Centro Universitário, Paripiranga-BA, Brasil \\ E-mail: profdavi@live.com
}

Recebido: 10/06/2021 - Aceito: 15/06/2021

\section{Resumo}

A preparação física possibilita um leque de contribuições para a melhora dos níveis do alto rendimento dos atletas perante as suas condições físicas, desde os aspectos da resistência, força, potência, velocidade, flexibilidade e agilidade. Nesse sentido, o presente trabalho tem como objetivo de abordar sobre a preparação física no rendimento do atleta de futebol. O estudo trata-se de uma pesquisa bibliográfica com abordagem qualitativa. Observou-se a preparação física no futebol moderno vem evoluindo e com isso surgiu a importância da preparação física nos aspectos fisiológicos, morfológicos e biopsicossociais do atleta. Nesse sentido, o preparador físico deve elaborar um planejamento organizacional, ressaltando as metas do clube de forma consistente e eficaz. Conclui-se que a preparação física e o trabalho do preparador físico são essenciais para contribuir no rendimento dos atletas de futebol.

Palavras-chave: futebol; preparação física; rendimento.

\section{Abstract}

Physical preparation allows a range of contributions to improve the levels of high performance of athletes in view of their physical conditions, from the aspects of endurance, strength, power, speed, flexibility and agility. In this sense, the present work aims to address the physical preparation in the 
performance of the soccer athlete. The study is a bibliographic research with a qualitative approach. It has been observed that physical preparation in modern football has been evolving and with this the importance of physical preparation has arisen in the athlete's physiological, morphological and biopsychosocial aspects. In this sense, the fitness coach must prepare an organizational plan, emphasizing the club's goals in a consistent and effective way. It is concluded that the physical preparation and the work of the physical trainer are essential to contribute to the performance of soccer athletes.

Keywords: football; physical preparation; performance.

\section{Introdução}

O futebol moderno teve sua origem no século XIX, sendo um segmento de entretenimento e lazer para as civilizações deste período, entretanto sua popularidade era reservada unicamente para pessoas da classe alta (CAFÉ, 2010). Para Leme et al. (2019), o futebol passou por modificações deixando de ser apenas uma fonte protagonista de entretenimento e lazer, mas também como fins do alto rendimento.

Nesse contexto, com o futebol de alto rendimento surgiu a necessidade de uma ferramenta de trabalho que contribuísse na melhora dos níveis do condicionamento físico dos atletas, destacando-se a preparação física.

A preparação física veio com o propósito de aprimorar o condicionamento físico dos jogadores, desde as categorias de base, amadores e profissionais, tendo em vista a melhoria dos níveis de performance dos mesmos, durante os treinamentos e competições (DANTAS, 2011).

A preparação física viabilizou a evolução dos atletas, principalmente, referente aos aspectos da força, resistência e velocidade, fatores estes relevantes para a atuação significativa dos atletas de acordo com suas funções em campo, elemento primordial para performance de seus jogadores entre os primeiros modelos de treinamento (LEME et al., 2019).

Nesse sentido, o estudo tem o objetivo de abordar sobre a preparação física no rendimento do atleta de futebol $E$, justifica-se em potencializar as discussões sobre a preparação física na melhora do desempenho do atleta. 


\section{Metodologia}

\subsection{Caracterização do Estudo}

O estudo trata-se de uma pesquisa bibliográfica com abordagem qualitativa. Conforme Prandov e Freitas (2013), a pesquisa bibliográfica é uma metodologia voltada para a linha de pesquisa da revisão da literatura, por meio dos artigos e livros, tendo como principal característica a interpretação científica a respeito da realidade social sobre o embasamento científico. Segundo Pranadov e Freitas (2013), a pesquisa mediante abordagem qualitativa é o espaço adequado para a coleta de dados, interpretação de fenômenos e atribuição de significados.

\subsection{Instrumentos para coletas dos dados}

Para realizar o levantamento bibliográfico foram utilizados livros e artigos científicos encontrados na base de dados do Google Acadêmico. Utilizou-se os descritores: preparação física; futebol; treinamento esportivo, foram considerados os seguintes parâmetros limitadores da busca inicial: a) artigos publicados entre 2004 e 2020; b) redigidos em língua portuguesa ou inglesa e, c) publicações que tivessem como foco a temática do estudo.

\subsection{Análise dos Dados}

Após levantamento preliminar em livros e em bases de dados escolhidos, o conteúdo dos livros e os resumos dos artigos selecionados foram analisados de modo a compor o corpus deste estudo.

\section{Revisão Bibliográfica}

No treinamento esportivo, a preparação física é uma das fases primordiais para melhora das condições da aptidão física dos atletas na etapa da prétemporada, viabilizando estimular inicialmente as respostas adaptativas do organismo humano a respeito de uma zona de esforço máximo, por meio de programas de treinamentos físicos organizados de forma gradual e voltados para o futebol moderno (DANTAS, 2014).

Para Barbanti (2017) a preparação física é a etapa crucial para o alto desempenho da equipe durante o período competitivo, pois a pré-temporada 
potencializa a melhora dos níveis da alta performance dos atletas, relacionando suas condições físicas desde os aspectos fisiológicos e morfológicos dos atletas, mediante as exigências do futebol contemporâneo.

A preparação física tem o objetivo de contribuir na melhoria das condições físicas dos indivíduos, desde as capacidades físicas as habilidades de cada atleta, correspondentes às suas necessidades e posições efetuadas dentro de campo (LEME et al. 2019).

O treinamento esportivo almeja, primordialmente, viabilizar o aprimoramento das condições físicas dos atletas da modalidade esportiva futebol, seja eles no âmbito amador ou profissional (GOMES, 2009). Ele viabiliza gerar o máximo de adaptações através dos estímulos externos corriqueiramente, sendo de grande valia para o prosseguimento do desenvolvimento da alta performance dos atletas em pleno espetáculo futebolístico, pois ele favorece metodologicamente as adaptações fisiológicas, morfológicas e psicológicas.

De acordo com Barbanti (2017), os princípios do treinamento esportivo são de extrema importância para organizar toda a estrutura do planejamento do clube em relação ao desenvolvimento dos atletas e suas competências diante sua formação, por meio das fases do jogo, relacionando os aspectos da defesa e ataque, viabilizando a melhora da performance dos jogadores.

Os princípios do treinamento esportivo são compostos pelo princípio da individualidade biológica, adaptação, continuidade, interdependência volume e intensidade, especificidade, além dos princípios de variabilidade e o da sobrecarga.

O princípio da individualidade biológica é um dos fatores determinantes dentre os aspectos funcionais do corpo humano, pois cada sujeito contém seu fator genético individualizado, subsídio fundamental para o desempenho da performance do esportista, seja no contexto profissional ou amador, do mesmo modo abrange as práticas corporais bem como atividades físicas e exercícios físicos, ambos caminhos enfatizam a atenção sobre a sistematização dos programas de treinamento, ou seja, individual e coletivo (DANTAS, 2014).

O princípio da adaptação é o momento ímpar perante o desenvolvimento das alterações fisiológicas, favorecendo as adaptações internas das reações do sistema metabólico na produção de substratos energéticos e, morfologicamente, o 
corpo vai se adaptando ao ambiente diante dos estímulos externos e internos no organismo, relacionando as dosagens das cargas de treinamento sistematizado, as quais possibilitam a melhora da aptidão física do sujeito de forma evolutiva e gradativa (OLIVEIRA, 2017).

O princípio da continuidade é o momento ímpar diante da formação do perfil do atleta ante suas adaptações fisiológicas, prosseguindo sucessivamente com os treinamentos, manipulando as cargas, ajustando a intensidade e o volume específico, diante as necessidades de cada jogador, entrepondo um trabalho de longo prazo (TEIXEIRA, 2019)

O princípio da interdependência volume-intensidade é um ponto crucial do treinamento esportivo que se denomina pela adequação essencialmente do volume no transcorrer do treinamento diante o controle da intensidade. Para Dantas (2011) esse princípio está relacionado também aos diversos preceitos da sobrecarga entrelaçando o volume e a intensidade da zona de treinamento das condições físicas, impondo as especificidades de cada sujeito.

O princípio da especificidade é o momento de vivenciar as diversas situações específicas de uma partida de futebol, por meio das sessões de simulações, relacionando diretamente com a realidade do jogo oficial, conduzindo nessa mesma prerrogativa os treinamentos técnicos e táticos para aprimorar as possíveis valências de cada jogador, perante suas necessidades de aptidão física, mediante suas funções em campo. Do ponto de vista de Praça e Greco (2020)

O princípio da variabilidade é a capacidade que abrange os diferentes tipos de estímulos externos durante os períodos de treinamento e jogo, e essas variáveis proporcionam respostas adaptativas que se dão ao longo das sessões das variabilidades de treinamentos e pelas experiências do esporte. Este princípio possibilita a melhora dos aspectos do desempenho físico e autonomia da tomada de decisão, sendo o principal elemento para efetivar uma ação motora durante o jogo taticamente, relacionando para além disso, o ambiente que o atleta esteja inserido na partida, favorecendo manter seu posicionamento sob o objetivo da vitória e mantendo seu foco sobre às diversas situações problemas que possam surgir no decorrer da partida (PEREZ, 2010).

O princípio da sobrecarga refere-se aos fatores determinantes para 0 
desenvolvimento da aptidão física, mediante a zona de esforço acerca da intensidade e volume do treinamento que geram adaptações significativas. Conforme Leme et al. (2019) é o princípio que determina o controle da intensidade e o volume do treinamento diante o planejamento do cronograma da periodização, sob o engajamento da zona de trabalho e do esforço físico na modalidade esportiva futebol favorece continuamente a melhora dos aspectos das condições da aptidão física de cada jogador.

Nesse contexto, destaca-se que a preparação física é um aspecto do treinamento esportivo, pois ambos melhoram as capacidades motoras que, de alguma maneira, influenciam no rendimento dos desportistas durante sua atuação em meio de uma partida ou no decorrer de uma temporada (BARBANTI, 2017).

\subsection{Treinamento das Capacidades Físicas}

O treinamento das capacidades físicas no futebol entrelaça os fatores do condicionamento físico referente as alterações fisiológicas do corpo humano em meio as exigências metabólicas determinadas durante o jogo. Desta maneira, simultaneamente o aperfeiçoamento da aptidão se dá através dos aspectos físicos, técnicos, táticos e psicológicos dos jogadores de futebol, favorecendo assim, a manutenção dos níveis elevados ante o período da competitividade, evidenciando ter excelentes resultado nas competições (HOFF, 2005).

As capacidades físicas no futebol são acentuadas como um conjunto de ações motoras de propriedades filologicamente do corpo humano, envolvendo o estado de saúde e o estado condicionante do jogador, fisicamente treinado de acordo com as exigências físicas de um jogo de futebol. As capacidades físicas são: resistência, força, potência, velocidade, agilidade e a flexibilidade (DANTAS, 2014).

A resistência é a capacidade que viabiliza o desenvolvimento do condicionamento da aptidão física tanto do sistema cardiovascular, quanto cardiorrespiratório, melhora a percepção de jogo, proporcionando ao mesmo tempo para o atleta uma atuação no decorrer da partida e treinos com mais eficiência, mantendo sua alta performance e permitindo do mesmo modo minimizar os possíveis níveis da fadiga física e mental (CARUSO, 2018). 
A força é uma capacidade de extrema importância para a realização dos movimentos, em suma, sobre as competências solicitadas e exigidas pela modalidade esportiva futebol, a respeito da efetivação da ação motora desde o passe, chute, cabeceio, sprints, saltos entre outros fundamentos (DANTAS, 2014).

A potência é uma capacidade de suma importância para a modalidade futebolística, ela permite ações do potencial neuromusculares fundamentais para atuação dos jogadores em campo, consequentemente, potencializando a melhora da funcionalidade dos picos dos sprints sob diversas situações de jogo (FAUDE, et. al 2012).

A velocidade é a capacidade que se conceitua pelas ações múltiplas e reações aceleradas de deslocamentos pelos aspectos da estimulação dos treinamentos em ambientes de espaçamentos curtos, bem como os trabalhos de campo reduzido, permitindo o aprimoramento do drible, raciocínio rápido e cognitivo do atleta. (DO NASCIMENTO, 2020).

A agilidade é a capacidade que enfatiza a movimentação do atleta e suas características de habilidades com a bola, que permite a facilidade de sobressair das situações de jogo e na construção de jogadas inteligentes (GANZER; RIBEIRO; DEL VECCHIO, 2016). Segundo Do Nascimento (2020), a agilidade é a capacidade do atleta reagir sobre uma situação de jogo de forma rápida desde os aspectos da movimentação, tendo uma noção dos espaços curtos ou amplos, usando suas habilidades motoras por meio dos adjuntos dos dribles.

A flexibilidade é a capacidade que permite as diversas realizações das amplitudes máximas dos movimentos, envolvendo os ângulos das articulações no futebol. Dessa forma, a capacidade da flexibilidade na modalidade tem seu papel de colaboração conceitual a respeito dos treinamentos do relaxamento muscular e na etapa da mobilidade articular dos movimentos motores, responsáveis pelas ações técnicas de jogabilidade dos atletas (DA CUNHA, 2004).

Essas capacidades físicas permitem aos atletas, principalmente, o desenvolvimento das adaptações fisiológicas desde os substratos bioenergéticos, provindos dos estímulos neurais e do estresse metabólico, fatores estes do mesmo modo determinantes para atuação dos jogadores em campo. 


\subsection{Periodização do Treinamento Esportivo}

A periodização do treinamento esportivo no âmbito futebolístico é primordial, pois está relacionada as adaptações das especificidades fisiológicas físicas dos sujeitos, desde suas ações motoras, cognitivas e afetivas, viabilizando assim, o auge dos níveis das condições físicas de cada atleta ante os períodos das competições.

A periodização é um dos fatores determinantes para o sucedimento da equipe diante dos períodos competitivos, pois tem o papel de planejar, organizar e priorizar os programas e treinamentos, conforme o embasamento científico de dados, entrelaçando especificidades das capacidades técnico-tácticas individuais e coletivas (PIVETTI, 2020).

Conforme Santos et al. (2011), essa etapa é o momento de suma importância para a organização e estruturação do planejamento da periodização. Barbanti (2017) divide em: preparatório, competitivo e transitório.

O período preparatório, nas primeiras semanas, está relacionado diretamente ao propósito de seu objetivo: desenvolver o condicionamento físico da resistência e força dos atletas, por isso é uma etapa fundamental para maximizar o treinamento das condições físicas dos jogadores, o mesmo efetuado durante uma semana pela comissão técnica antes do início da pré-temporada (BARBANTI, 2017). Esse período engloba os testes físicos, médicos, dentre outras ferramentas de monitoramento, pois facilitam a coleta de informações de forma precisa a respeito de cada jogador, almejando o desenvolvimento eficaz para a temporada.

O período competitivo no futebol é uma fase que apresenta um caráter de engajamento a respeito da preparação física continuada, por ser bastante exigente e extenso, engloba sua ênfase sobre o calendário acumulativo de jogos, descanso e variações de intensidades sobre as sessões de treinamento ante peculiaridades das condições físicas específicas, envolvendo a modalidade esportiva futebol, relacionando também os trabalhos técnicos e táticos da equipe (CAMPOS, 2017).

O período competitivo colabora diretamente no desenvolvimento do atleta perante as suas funcionalidades dentro de campo, dispondo assim, da sequência de atuações em jogos, contribuindo diretamente para a melhora dos níveis da aptidão física (PIVETTI, 2020). 
Já o período da transição, é caracterizado pela recuperação dos sistemas central e periférico do atleta, pois existirá perda do condicionamento físico pela situação da pausa do calendário para as férias. No entanto, este viés, é usado para a nova elaboração do planejamento para a próxima temporada (LEME, 2019).

Para Campos (2017), no futebol o planejamento no período da transição favorece uma gama de benefícios para a recuperação tanto do sistema periférico, tecidos musculares danificados, quanto para a reposição dos subsídios dos sistemas bioenergéticos, os quais são de suma importância para a performance dos atletas durante os treinos e partidas oficiais.

Entende-se que a etapa de preparação das condições físicas necessita de embasamento científico suficiente, para o prosseguimento do planejamento seguro da definição dos ciclos a serem trabalhados nos períodos da pré-temporada, competitivo e transitório, juntamente com os princípios do treinamento esportivo, tendo uma programação, organização e controle do planejamento (DANTAS, 2014).

A organização da periodização parte do planejamento do macrociclo, mesociclo e microciclo. O macrociclo é caracterizado como o todo do planejamento, incluindo além disso os diversos mesociclos ( 3 a 4 por temporada), pois cada um desses é constituído pelas etapas da prescrição dos microciclos (DANTAS, 2014). Na visão de Pivetti (2020) o macrociclo é a etapa da realização dos cronogramas semanais estabelecidos no planejamento organizacional da temporada, incluído pela comissão do clube, enfatizando tanto os períodos da pré-temporada e, gradualmente, pelo calendário esportivo, a aplicabilidade relaciona os procedimentos dos mesociclos e microciclos diários.

Para Barbanti (2017) o macrociclo é a fase do planejamento que engloba o todo da periodização dos programas de treinamentos desde os aspectos do mesociclo e os microciclos, pontos estes principais para estabelecer o que será trabalhado durante uma a duas temporadas de forma adequada e flexível, ressaltando ainda os níveis do condicionamento físico de cada atleta e os períodos do calendário pré-competitivo e competitivo.

O mesociclo é a fase que possibilita a elaboração da periodização organizacional entre 3 a 6 semanas, perante o retorno dos atletas de férias na pré- 
temporada sob o enfoque de estimular o aprimoramento das condições físicas, tendo em vista a melhora da performance para o período competitivo, juntando os aspectos da manutenção de condicionamento, prevenção de lesões, refinamento tático e o trabalho regenerativo (DANTAS, 2014).

Esse ciclo possibilita organizar especificamente as zonas de treinamentos de 3 a 6 semanas, possibilitando também a inclusão das fases preparatória e competitiva, viabilizando o desenvolvimento dos trabalhos estratégicos sob situações dos próximos jogos taticamente, conduzindo a melhora da aptidão física dos jogadores (PIVETTI, 2020).

Já o microciclo, caracteriza-se entre 2 a 5 semanas por ser a menor parcela da integração da periodização das sessões de treinamento, esse procedimento varia em meio a proeminência da capacidade a ser cogitada (LEME et al., 2019). Os microciclos facilitam a progressão das zonas das cargas de treinamento em meio as evoluções dos jogadores, além disso, são importantes para reajustar as especificidades da performance ainda em baixo nível na apresentação do seu retorno de lesão, para um procedimento recuperativo de alto rendimento (DANTAS, 2014).

Nesse contexto, os métodos dos treinamentos neste andamento da modalidade esportiva futebol são imprescindíveis para o desenvolvimento das condições físicas dos atletas, por meio dos três eixos metodológicos: contínuo, fracionado e intervalado.

Eles são utilizados para fins do treinamento esportivo sobre a escolha da metodologia adequada para fins do alto rendimento. Jogadores na etapa da preparatória, viabilizando o refinamento da aptidão física (individual a coletiva). Entretanto, sua aplicabilidade permite gradualmente a geração das adaptações cognitivas, fisiológicas e morfológicas referente aos aspectos das habilidades técnicas e táticas (BARBANTI, 2017).

O método contínuo é uma metodologia que se caracteriza pela conduta do envolvimento da zona alvo do treinamento entre sua relação com a frequência cardiovascular, voltada para o aprimoramento da capacidade física dos atletas em meio ao limiar aeróbico pelos exercícios cíclicos, dispondo a melhora da capacidade $\mathrm{VO}^{2}$ máximo e, possibilitando, maior prolongação na prática esportiva 
em alto nível (DANTAS, 2014).

Para Barbanti (2017), o método contínuo é a continuidade do processo das adaptações físicas dos atletas sobre a percepção e a manipulação das variáveis da intensidade em meio a zona do esforço, conforme o volume de tempo é diminuído de forma uniforme proporciona o equilíbrio constantemente da zona do esforço do atleta, enfatizando sempre otimizar os diversos tipos de adaptações fisiológicas e específicas, exigidas pela modalidade desportiva futebol, como na reconstrução do tecido muscular e na melhora do sistema circulatório e cardíaco.

O método intervalado tem a estratégia/aplicação da pausa do treino ou conhecida como tempo para descanso recuperativo. Todavia, esta pausa influencia no controle da zona do esforço entre a intensidade e o volume, contribuindo eficientemente para a reposição dos substratos energéticos, os quais são importantes para a realização da repetição da sessão de treinamento ou circuitos (BARBANTI, 2017).

Nota-se que sua conduta se embasa pelos pontos cruciais a respeito das experiências dos jogos reduzidos ou espaçamentos reduzidos, relacionando além disso os intervalos fracionados, ou seja, seu objetivo é trabalhar a pausa durante as séries e repetições das sessões de treinamento, de forma minimizadas por meio das manipulações das intensidades baixas, moderadas e altas, viabilizando a recuperação dos atletas.

Evidencia-se que esse método contribui diretamente na recuperação da performance dos atletas por meio das ações fracionadas, entrepondo os diversos ritmos de jogos, simulando ao mesmo tempo as situações de jogo por meio dos espaçamentos reduzidos, possibilitando a formação das características dos jogadores através das pausas ou intervalos nos períodos da zona do esforço, acarretando a recuperação dos estoques de energias, fundamentais para o sucedimento em campo (BRAZ; BORIN, 2009).

Nesse sentido, o aprimoramento das capacidades da resistência, potência, força, velocidade, agilidade e flexibilidade são de suma importância para o futebol moderno, conforme os estímulos mecânicos são trabalhados em meio as zonas de treinamentos, viabilizam suprir as valências identificadas de cada atleta (LEME et al., 2019). 


\subsection{O Preparador Físico}

A atuação do preparador físico é essencial no processo de manipulação da intensidade e o volume, tempo de durabilidade dos treinamentos, sendo um fator determinante para a progressão gradativa desses jovens atletas, respeitando seus coeficientes da individualidade biológica, de cada criança e adolescente que estejam inseridos neste âmbito esportivo do futebol, bem como em outras modalidades esportivas como: voleibol, futsal, handebol, basquetebol entre outras modalidades (PIVETTI, 2020).

Todavia, a montagem dos programas de treinamento nas categorias de base e no profissional necessitam ser bem-organizados, respeitando as limitações de cada atleta dentre os princípios do treinamento esportivo, visando gradualmente a melhora dos níveis dos fatores condicionantes da aptidão física ante seu desenvolvimento de alta performance (DANTAS, 2014).

Desse modo, a montagem do treino busca reduzir os números das possíveis lesões dos sistemas musculoesquelético, ósseo e articular, nesta ocasião podem ser evitadas pela concepção de um planejamento estruturado mantendo sua organização e enfatizando o equilíbrio através da manipulação lógica da zona de trabalho do esforço físico, relacionando a especificidade da intensidade e do volume do treinamento das cargas no futebol. Nota-se que se beneficia assim, a melhora da performance e ao mesmo tempo, a diminuição de possíveis lesões musculares e articulares (RAJIC; GRUBIC, 2018).

O preparador associa do mesmo modo os níveis do condicionamento físico juntamente com as condições físicas de cada atleta no período recuperativo, pois é uma ocasião de suma importância para a recuperação dos jogadores de futebol, após os treinamentos, jogos e as temporadas (DANTAS, 2014).

Assim, o preparador físico perante seu campo de atuação no futebol é o único profissional habilitado para planejar, prescrever e orientar a pré-temporada da preparação física, devido a sua linha de formação de graduação e Educação Física abrangendo várias concepções de conhecimento em sua bagagem profissional desde os caminhos científicos da anatomia, fisiologia, fisiologia do exercício, nutrição desportiva, cinesiologia, biomecânica entre outras áreas de relevância 
Revista Multidisciplinar do Nordeste Mineiro, v.2,

2021/02

ISSN 2178-6925

para a contemplação do desenvolvimento dos atletas na modalidade esportiva futebol.

\section{Considerações Finais}

A preparação física no futebol moderno vem evoluindo e com isso surge a importância da preparação física nos aspectos fisiológicos, morfológicos e biopsicossociais. Nesse contexto, o preparador físico deve elaborar um planejamento organizacional, ressaltando as metas do clube de forma consistente e eficaz, através dos seguintes períodos: pré-competitivo, competitivo e transitório.

O profissional deve estar embasado sobre as ferramentas de trabalho as quais envolvem a preparação física, por exemplo, a avaliação física, o monitoramento e o aprimoramento das capacidades físicas referentes às condições dos atletas.

Em suma, a preparação física no futebol é essencial para o desenvolvimento da performance dos jogadores, pois contribui na otimização dos níveis das condições físicas e psicológicas dos atletas, favoráveis para potencializar, progressivamente, o aperfeiçoamento do rendimento em pleno alto nível competitivo.

\section{Referências}

BARBANTI, Valdir J. Teoria e prática do treinamento esportivo. Editora Blucher, 2017.

BRAZ, T. V.; BORIN, J. P. Análise quantitativa dos jogos de uma equipe profissional da elite do futebol mineiro. Revista da Educação Física/UEM, v. 20, n. 1, p. 33-42, 2009.

CAFÉ, Lucas Santos. Futebol Poder e Política. I Encontro de História do CAHL Centro de Artes, Humanidades e Letras. Quarteirão Leite Alves, Cachoeira-BA, 2010.

CAMPOS, Luis Felipe Castelli Correia de et al. Futebol de 5: os efeitos da estruturação e distribuição da carga de treinamento nas variáveis de desempenho motor. 2017.

CARUSO, Fabiola Gaio et al. Efeitos de sete semanas de treinamento no período preparatório de jovens futebolistas. 2018. 
DANTAS, Estélio H. M. A prática da preparação física. Estélio Henrique Martin Dantas. 6. ed. - Vila Mariana, SP: Roca, 2014.

DANTAS, Estélio Henrique Martin et al. Adequabilidade dos principais modelos de periodização do treinamento esportivo. Revista Brasileira de Ciências do Esporte, v. 33, n. 2, p. 483-494, 2011.

DA CUNHA, M. Fabio Aires. Características, importância e treinamento da flexibilidade no futebol. 2004.

DO NASCIMENTO, Fabrício Henrique Ferreira et al. Velocidade e força em jogadores de futebol: análise exploratória/Speed and strength in soccer players: exploratory analysis. Brazilian Journal of Development, v. 6, n. 2, p. 8371-8379, 2020.

FAUDE, Oliver; KOCH, Thorsten; MEYER, Tim. Straight sprinting is the most frequent action in goal situations in professional football. Journal of sports sciences, v. 30, n. 7, p. 625-631, 2012.

GANZER, Vinicius Rosa; RIBEIRO, Yuri Salenave; DEL VECCHIO, Fabrício Boscolo. Análise da aptidão física de jovens praticantes de futebol: efeitos do período de preparação e titularidade competitiva. RBFF-Revista Brasileira de Futsal e Futebol, v. 8, n. 29, p. 142-154, 2016.

GOMES, Antonio Carlos; DE SOUZA, Juvenilson. Futebol: treinamento desportivo de alto rendimento. Artmed Editora, 2009.

HOFF, Jan. Training and testing physical capacities for elite soccer players. Journal of sports sciences, v. 23, n. 6, p. 573-582, 2005.

LEME, Lucas C. et al. Preparação Física no Futebol. Futebol Interativo. 1. Ed. Natal-RN, 2019.

OLIVEIRA, Patrícia Chaves Antunes. Testes físicos para avaliação da agilidade: possibilidade de adaptação ao futebol. Revista Brasileira de Futebol (The Brazilian Journal of Soccer Science), v. 8, n. 2, p. 65-75, 2017.

PEREZ, Anselmo José. Quem são os atletas e os não-atletas no processo de treinamento. Revista Brasileira de Ciências do Esporte, v. 21, n. 2, 2010.

PIVETTI, Bruno MF. Periodização tática: o futebol-arte alicerçado em critérios. Phorte Editora, 2020.

PRAÇA, Gibson Moreira; GRECO, Pablo Juan. Treinamento tático no futebol: teoria e prática. Editora Appris, 2020.

PRODANOV, C. C.; FREITAS, E. C. de. Metodologia do trabalho científico [recurso eletrônico]: métodos e técnicas da pesquisa e do trabalho acadêmico. 2. ed. Novo Hamburgo: Feevale, 2013.

RAJIC, Fabijan; GRUBIC, Marko. The Impact of Chaging the Coach on Injuries in Profesional Sport- Exemple from Practice. Journal of Health Science, v. 6, p. 159-162, 2018. 
Revista Multidisciplinar do Nordeste Mineiro, v.2,

2021/02

ISSN 2178-6925

SANTOS, Pedro; CASTELO, Jorge; SILVA, Pedro Miguel. O processo de planejamento e periodização do treino em futebol nos clubes da principal liga portuguesa profissional de futebol na época 2004/2005. Revista brasileira de educação física e esporte, v. 25, n. 3 , p. 455-472, 2011.

TEIXEIRA, Jorge Daniel Fernandes Moreira. Otimização Desportiva no Futebol: a operacionalização no processo de Formação. 2019. 